\title{
Sociological Research on Teachers' Emotions: Four Approaches and the Shared Themes
}

\author{
Kwok Kuen Tsang \\ Caritas Institute of Higher Education \\ Hong Kong
}

Email: gkk1212@gmail.com

Doi:10.5296/ jsr.v6i2.8749 URL: http://dx.doi.org/10.5296/ jsr.v6i2.8749

\begin{abstract}
During the mid-1990s, teachers' emotions emerged as an area of research in the sociology of education because many teachers all over the world were reported to be unhappy, dissatisfied, stressed, frustrated, and even alienated. This implies that teachers' emotions, especially negative ones, go beyond individual factors and have become a social issue. Therefore, researchers use sociological perspectives and theories to deepen our understanding of the phenomenon. In order to advance our understanding of the social construction mechanism of teachers' emotions, this article reviews four sociological approaches of teachers' emotions: labor process of teaching in the context of education reforms, emotion management in teaching, social interaction in school settings, and teacher identity.
\end{abstract}

Keywords: Teachers' emotions, education reforms, labor process, emotional labor, teacher identity 


\section{Introduction}

Since the mid-1990s, teachers' emotions have become a crucial issue across the globe (Day \& Lee, 2011; Nias, 1996; Schutz \& Zembylas, 2009; Sutton, 2005; Tsang, 2014). One likely reason for this is that more and more teachers all over the world have been identified as feeling stressed, depressive, frustrated, dissatisfied, unhappy, and even alienated (Hargreaves, 2003; Kelchtermans, 2011; Leithwood \& Beatty, 2008; Morgan, Ludlow, Kitching, O'Leary, \& Clarke, 2010; Santoro, 2011; Saunders, 2013; Trentini, 2012). In other words, teachers' emotions, especially negative emotions, should be considered as a social rather than a purely psychological issue. Thus, sociological imagination is required to deepen our understanding of teachers' emotions.

Generally, the sociologists of teaching are interested in how teachers' emotions are socially constructed or caused (Tsang, 2013, 2014). Their research findings indicate a range of mechanism of social construction of teachers' emotions because of different theoretical perspectives they have adopted (as we shall see below). It seems to suggest that teachers' emotions are a complicated phenomenon so it is impossible to have an integrated framework to understand and explain the phenomenon. Nevertheless, we may identify common themes shared by the studies if we take a close look at and a careful investigation of the literature. The shared themes may reflect the important dimensions of the mechanism of social construction of teachers' emotions. Therefore, the aim of this article is to review the existing sociological studies of teachers' emotions in attempt to advance our understandings of teachers' emotions.

Although the sociologists can approach teachers' emotions differently, four common approaches have continuously recurred in the literature. They approaches include labor process of teaching in the context of education reforms, emotion management in teaching, social interaction in school settings, and teacher identity (Tsang, 2013, 2014). Thus, this article only pays attention to them. In the following, the article attempts to review the theoretical perspectives, concerns and major arguments of each approach in order to identify the themes about the social construction mechanism of teachers' emotions.

\section{Labor process of teaching in the context of education reforms}

It is argued that this is the traditional approach to teachers' emotions in the sociology of education, although the major concern of this approach is not about teachers' emotions (Tsang, 2014). Since the 1980s, sociologists of education have criticized education reforms all over the world for its tendency to transform the labor and labor process of teachers in such as a way that they resemble those of industrial workers, resulting in poor working conditions and lives for teachers, such as heavy workload and the lack of leisure time (Apple, 1982; Hargreaves, 1994; Harris, 1994; Robertson, 2000). In order to improve the situation, sociologists of education have investigated how education reforms transforms labor and the labor process in teaching. This kind of research is generally called labor process theory (Smyth, Dow, Hattam, Reid, \& Shacklock, 2000). Although labor process theory does not directly deal with teachers' emotions, it offers insights into how teachers' emotions may be affected by education reforms. 
According to labor process theory, many states in the world have attempted to increase external control over teachers' work in order to promote high quality of education, which in turn supports the development of the state (Smyth et al., 2000). Labor process theorists have found that states may increase external control through two transformation processes of labor: deskilling and intensification.

Deskilling is the process of devaluing and degrading teachers' work, which in turn results in teachers being unable to define and design what they do at work. Labor process theory argues that education reforms may contribute to this process. First, education reforms always involves a curricular reform that may standardize the teaching and learning process in every classroom (Smyth et al., 2000). For example, a state may implement a national curriculum that defines what subject knowledge teachers should teach and how students should be assessed. In order to make sure that teachers follow the curricular requirements, the state may provide prepackaged curricular materials, such as textbooks, to every teacher. Apple (1982, 1986) and Harris (1982) finds that prepackaged curricular materials include not only teaching contents and materials but also teaching plans. Therefore, teachers can simply teach lessons by using the prepackaged curricular materials without having to expend any effort to design and plan their lessons. Moreover, Connell (1995) notes that education reforms may aim to enhance the status of public examinations. Consequently, teachers may need to follow the teaching progress stated by the national curriculum and syllabus strictly so as to ensure that their students can pass high-stakes public examinations (Ball, 1994). In this situation, teachers may need to teach students how to pass the examinations rather than take care of students' whole-personal development (Anagnostopoulos, 2003; Comber \& Nixon, 2009). As a result, teachers may become more dependent on prepackaged curricular materials in order to avoid the risk of student failure in examinations (Smyth et al., 2000). In this sense, teachers become less able to control and design their teaching process in the classroom.

The second force of deskilling is managerialism. Educational researchers have identified many education reforms across the globe as being based on managerialism(Hargreaves, 2003). This kind of reforms tries to introduce market logics for the operation of state education (Mok \& Welch, 2002). For example, managerialist education reforms emphasize the concepts such as quality, accountability, competition, efficiency, clients, and quality assurance (Tse, 2005). A notable outcome of this kind of reforms is that teachers are subject to more and more supervision and monitoring from the government and the community. Although this kind of reform tends to transfer responsibility for educational problems to individual schools and teachers, the government may be concerned that schools and teachers may perform poorly, so it attempts to make schools and teachers more accountable through external evaluations and inspections (Ball, 1994). One notable example is Hong Kong. Since the late-1990s, the Hong Kong government has intensified its inspection and supervision of schools and teachers by implementing several initiatives such as: School Self Evaluation (SSE) and the External School Review (ESR) in 2003, the Quality Assurance Inspection (QAI) in 1997, and Language Benchmarks Tests for teachers in 2000 (Tse, 2005).

On the other hand, managerialist reforms may also create a quasi-market in education through initiatives such as school choice and accountability to stakeholders (Whitty, 2002). In this 
quasi-market, schools and teachers become service producers, who have to adjust their work to satisfy and meet the demands and expectations of their clients - students and parents (Smyth et al., 2000). To some extent, manageralism tends to decrease teachers' power to control their labor process by putting them into a subordinate position with respect to the government, the community, and parents.

As teachers become deskilled and lose their control over their labor and the labor process, it becomes difficult for them to reject the extra duties imposed upon them (Apple, 1986). Thus, labor process theory claims, intensification of work is inevitable for the teaching profession (Apple, 1986). For example, a study conducted by the OECD (2005) reports that teachers in the OECD countries were required to take on many responsibilities in addition to classroom teaching, such as guidance and discipline, organization of extracurricular activities, preparation of school-based teaching and learning materials, management of the school's public image, documentation, and writing reports for school internal and external inspection, and other administrative duties. As a result of so many duties and responsibilities, teachers may face work overload, lack leisure time, and feel stressed, and burnt out (Dworkin, 2002; Harris, 1994; Jeffrey \& Woods, 1996). Moreover, studies suggest that intensification also causes teachers to experience certain negative emotions at work, such as frustration, and a sense of meaninglessness and powerlessness, because they perceive that they are forced to do many things (e.g. school promotion, report writing, and documentation) that they consider unrelated to teaching and education and have no educational value (Ball, 2003; Hargreaves, 2003; Nias, 1999; Woods, 1999).

In sum, labor process theory suggests that education reforms may deskill and intensify teachers' work. Deskilling may result in teachers losing their control over their labor and the labor process of teaching, in which case intensification may occur. Intensification can lead to poor working conditions for teachers, such as heavy workload and lack of leisure time, so teachers may become stressed and burnt out at work. Although the theory does not directly discuss the issue of teachers' emotions, it does imply that education reforms may arouse teachers' negative emotions through deskilling and intensification. This is because the two processes together may lead to teachers being unable to define and design what they do in schools, and therefore being forced to do a lot of work and duties that they think are irrelevant to teaching and that they dislike. As a result, they may feel dissatisfied, frustrated, powerless, and meaningless, and even alienated when they do their work.

\section{Emotion management in teaching}

One of the prevalent research interests concerning teachers' emotions is about emotion management in teaching (Truta, 2013). To some extent, this approach aims to explore the nature of teaching and its impact on teachers' psychological and emotional well-being. The approach is inspired by Hochschild's(1983)work, which isrooted in Goffman's dramaturgical perspective and a Marxist perspective. On the basis of the dramaturgical perspective, Hochschild noted that emotional culture consists of feeling and expression rules specifying how we should feel and display our feelings in every social setting. For example, feeling and expression rules specify that people should be sad and should not smile at funerals, but that 
people should be happy and should not cry at weddings (Denzin, 1984). If social actors cannot adjust their feelings and displays according to feeling and expression rules, they will be perceived as emotional deviants by others (Thoits, 1990). To avoid becoming emotional deviants, people need to manage their emotions and displays appropriately. Hochschild referred to emotion management as emotion work and identified two strategies of emotion work: surface acting and deep acting. Surface acting involves modifying one's emotional display in accordance with what is expected in a particular situation regardless of one's actual feelings, whereas deep acting involves trying to change one's feelings to match the appropriate emotional display.

To some extent, emotion work is a normal act occurring in social actors' private lives. However, from the Marxist perspective, Hochschild(1983) pointed out that emotion management is not only an act occurring in one's private life, but also the work done for a wage in post-industrial societies. She found that more and more enterprises, especially service-related, sold employees' emotional activities for profit making. In such a situation, employees are no longer able to exercise control over their feelings and displays. For example, Hochschild(1983) illustrated how flight attendants are required by their employers to keep smiling and show warmth towards consumers because smiling and warmth are the selling points of airlines. Other studies have also had similar findings among other frontline service workers (e.g. waitresses and insurance sales), caregiving workers (e.g. retail clerks and child care workers), professionals (e.g. physicians and lawyers), and public service workers (e.g. social workers and corrections officials) (Wharton, 2009). In other words, many people in post-industrial societies have to manage their emotions under supervision. Hochschild(1983) referred to this kind of act as emotional labor: emotion management done for a wage. One possible consequence of emotional labor is emotional dissonance, which is the separation of feelings from displays(Hochschild, 1983). The higher the degree of emotional dissonance, the higher the degree of dehumanization, self-alienation, depersonalization, depression, and burnout (Ashforth \& Tomiuk, 2000; Diefendorff, Richard, \& Yang, 2008; Hopfl \& Linstead, 1993; Lewig \& Dollard, 2003).

Generally, sociological studies on emotional labor suggest that it is more likely that workers who are required to engage in face-to-face interactions with the public with love and care perform emotional labor (Wharton, 2009). Accordingly, educational researchers have argued that teachers are required to perform emotional labor because they need to interact face-to-face with students with love and care (Chen, 2015; Hargreaves, 1998a; Isenbarger \& Zembylas, 2006; Winograd, 2003). On the basis of the theory of emotional labor, the first task for educational researchers is to illustrate how teachers lose their control over their emotions in teaching. Tsang (2011) pointed out that while there may not be explicit supervision over teachers' emotions in teaching, teachers' emotions are prescribed by different feeling and expression rules of teaching. According to Zembylas(2005), the general rule requires teachers to avoid expressing too strong and too weak emotions. More specifically, Winograd(2003, p. 1652) revealed five feeling and expression rules for teachers:

(1) to love and to show enthusiasm for students; 
(2) to be enthusiastic and passionate about subject matter;

(3) to avoid the display of extreme emotions like anger, joy and sadness;

(4) to love their work; and

(5) to have a sense of humor and laugh at their own mistakes and the peccadilloes of students.

The rules may also be related to teacher professionalism. This means that if teachers do not manage their emotions appropriately according to the rules, they will be treated as unprofessional (Zembylas, 2005). Consequently, teachers have to perform emotional labor. Basically, this argument is accepted by most of education researchers. Since they agree that teachers need to perform emotional labor, they investigate the outcomes of the emotional labor in teaching with respect to teachers' psychological well-being and mentality.

According to the Marxist perspective, emotional labor is alienating (Scott, 1998). In other words, emotional labor creates emotional dissonance resulting in job stress, emotional exhaustion, burnout, or other negative outcomes. Many empirically studies provide support for this proposition. For example, the survey studies conducted by Hu"lsheger, et al. (2010), Iltaf and Gulzar(2013), and Na“ring, Brie"t and Brouwers(2006) show that emotional labor may cause teacher stress and burnout, a sense of depersonalization, and turnover. In addition, the ethnographic studies of Zembylas(2004a, 2004b, 2005) resulted in similar findings. These studies demonstrated that emotional labor in teaching may result in teachers' feelings of frustration, guilt, and shame, which in turn damage teachers' identity, confidence and self-esteem. For example, a teacher may dislike or even hate a student whose academic performance is bad or whose misconduct is serious. However, the teacher needs not only to suppress his or her negative emotions, but also to show love and care to the students because of the feeling rules. The suppression of negative emotions may create further negative emotions for teachers, such as guilt, regret, and shame, because they may think that it is inappropriate or even immoral for them as teachers to dislike or hate students (Hebson, Earnshaw, \& Marchington, 2007; O'Connor, 2008). In addition, teachers may also feel emotionally uncomfortable or self-estranged, because their displayed emotions do not correspond to their true feelings (Hu"lsheger et al., 2010; Philipp \& Schu"pbach, 2010). Both conditions may affect their professional identity and self-esteem, which in turn creates other intense negative emotions like frustration and depression (Hargreaves, 1998a; O'Connor, 2008).

On the other hand, some recent studies on emotional labor and management in teaching have provided opposite findings and conclusions. For example, the studies conducted by Hebson, et al. (2007),O'Connor (2008), Oplatka(2007), and Yuu(2010) found that teachers may feel satisfaction, excitement, and even self-fulfillment when they successfully manage their emotions at work. These studies imply that the Marxist assumption that emotional labor in teaching is alienating may be inaccurate (Hebson et al., 2007). One explanation is that the Marxist perspective tends to neglect teacher agency. Helsby(1999) showed that teachers are reflexive agents, who can independently and reflexively interpret, judge and decide what they 
should do and how they do their work in schools. In other words, emotional labor and management in teaching may not necessarily be forced labor. Instead, it may be a voluntary practice (Oplatka, 2007). For instance, Gong, Chai, Duan, Zhong and Jiao (2013) indicated that Chinese teachers may purposively regulate their emotions in teaching in order to achieve their instructional goals. Yuu(2010) found that Japanese teachers may choose to display anger to students, even though they are not angry, because they think such emotion management is an effective means to control students and help them concentrate on learning. Oplatka's(2007) study on Israeli teachers' emotional experiences also suggested that teachers may unconditionally express and show their love and care to students because the emotional displays are meaningful and valuable for them in developing relationships with students and in fostering students' growth. His more recent research suggests that if teachers do not manage their emotions in order to facilitate students' learning and growth, they may perceive themselves as immoral and unethical, resulting in negative emotions such as guilt and shame (Oplatka, 2009).

Accordingly, the research on emotion management in teaching highlights the nature of teaching as an interactive work with love and care that involves emotional culture consisting of feeling and expression rules. The emotional culture may constrain teachers' feelings and displays of feelings at work, and this constraint may create emotional dissonance resulting in negative emotional experiences and outcomes. On the other hand, studies on teachers' emotional labor and management illustrate that if teachers think emotion management is conducive to teaching and learning, they may feel positively about engaging in the practice.

\section{Social interaction in school settings}

In addition, the sociologists of education also investigate the social construction process of teachers' emotions from interactionist perspective (Yin \& Lee, 2011). Basically, this approach has become popular since the 1990s, because the power relations of teachers to other social actors in school systems have been fundamentally altered by different initiatives of educational changes, such as marketization and decentralization of education (Blase, 2005). Different from the research on labor process of teaching in the context of education reforms, the research on social interaction in school settings pay much attention to the process whereby teachers' emotions construct and are constructed by social interaction with students, parents, and colleagues. One of the influential theorists, perhaps the most important one, in this line of thought should be Andy Hargreaves (Evans, 2011; Yin \& Lee, 2011)

Based on interactionist perspective, Hargreaves (1998a, 1998b, 2000, 2001a, 2001b, 2002, 2003) believed thatemotions are constructed by the social interactions of teachers with students, parents, and colleagues, and that in turn the emotions will produce and reproduce the social interactions. Therefore, he has attempted to investigate the relationship between teachers' emotions and social interactions in school settings in order to improve the quality of teaching and learning.

More specifically, Hargreaves developed his theoretical framework of teachers' emotions from Denzin's (1984) interactionisttheory of emotions. According to this theory, teaching should be regarded as an emotional practice because teaching will activate, color and express 
not only teachers' feelings and actions, but also the feelings and actions of those with whom teachers interact (Hargreaves, 1998a). As an emotional practice, teaching requires extensive degrees of emotional understanding, which is the capacity to interpret and comprehend subjectively other people's emotions from one's own standpoint (Denzin, 1984). Without emotional understanding, mistrust and conflicts may permeate social relations between teachers and other school members, and in turn arouse negative emotions in them, which then affect social relationships. In order to facilitate social interaction, it is important to enhance emotional understanding between the interacting parties (Denzin, 1984). To enhance emotional understanding, Hargreaves proposed the concept of emotional geographies of teaching, which refers to "the spatial and experiential patterns of closeness and/or distance in human interactions and relationships" (Hargreaves, 2001b, p. 1061). The emotional geographies of teaching include five dimensions:

(1) Sociocultural geography: the similarities and differences in cultural and social backgrounds between teachers and those with whom they interact;

(2) Moral geography: the degree to which teachers' purposes are supported or appreciated by others;

(3) Professional geography: the degree to which teachers hold the norms of professional interaction that prescribe coolness, reserve and emotional distance among interactants;

(4) Political geography: the differences in power and status between teachers and those with whom they interact;

(5) Physical geography: the frequency, intensity and formalization of interactions of teachers with others.

Hargreaves noted that varying the degree of each dimension will influence the overall pattern of closeness/distance in social interactions and relations. As a result, emotional understanding will also be affected. Based on this framework, Hargreaves investigated teachers' emotions in different kinds of social interactions by conducting large scale ethnographic studies in which he observed 15 varied schools of different levels and sizes and also interviewed more than 60 elementary and secondary teachers in Canada.

With respect to teacher-student interaction, Hargreaves (2000) found that the elementary teachers tended to possess professional warmth and interacted frequently with students. According to Hargreaves, this may enhance the physical and professional closeness between teachers and students, and this closeness, to some extent, is the basis for the development of emotional understanding between teachers and students. On the other hand, Hargreaves also argued that the unequal social position between these two groups of people (i.e. teachers are dominant and students are dominated in the classroom) may create conflicts between them (political distance). This conflict may prevent them from developing shared emotional goals and emotional bonds, so emotional misunderstanding may occur among them (Hargreaves, 2000). However, Hargreaves (2000) thought that this political distance can be minimized if teachers and students can have more activities outside the core process of teaching and learning in classroom. This is because such activities make possible shared positive 
emotional experiences for both teachers and students, such as exhilaration and enjoyment.

Regarding teacher-parent relationships, Hargreaves (2001b) showed that teachers and parents are emotionally distant. This emotional distance is to some extent the result of (1) the difference in socio-cultural backgrounds between teachers and parents (sociocultural distance), and (2) the norm of teacher-parent interaction that prescribes coolness, reserve and emotional distance (professional distance). Sociocultural and professional distance prevents teachers and parents from developing shared understanding cognitively and emotionally. This may further foster moral distance between them, which means that parents may not understand, support, appreciate and respect how teachers carry out their classroom teaching. Consequently, teachers may feel that they have lost their professional status and power/authority (political distance). In such a situation, teachers may experience negative feelings such as anger, resignation, depression, and anxiety. In this case, it is possible that they either avoid interactions with parents or display emotions like hostility, anger and dissatisfaction towards parents. As a result, the conflicts and emotional distance between teachers and parents become deeper, and the emotional understanding between them also becomes weaker (Hargreaves \& Lasky, 2004).

Finally, Hargreaves (2001a, 2002) found that teachers tend to value peaceful working environments in which they may receive and enjoy rewards such as more social support and acceptance, so they should try to maintain harmonious relationships and avoid conflicts with colleagues. To achieve this, many teacherstry to respect or value what their colleagues do in order to shorten moral distance (Hargreaves, 2001a). In addition, they also try not to criticize their colleagues because this act may downplay colleagues' professional status and power/authority (Hargreaves, 2001a). In other words, they try to maintain political closeness. As a result, emotional understanding and positive social relationship among them may be developed. Hargreaves (2002) pointed out that if such emotional understanding and relationship cannot be fostered, it is possible for mistrust and betrayal to occur.

As we have seen, Hargreaves has illustrated in detail the emotional lives of teachers in face-to-face interactions. From his studies, we understand that teachers' emotions may be determined by teachers' sociocultural, moral, professional, political, and physical distance from students, parents and colleagues. On the other hand, teacher emotions may also affect further social interaction between teachers and those they interact with.

\section{Teacher identity}

Teacher identity has become an important topic in the field of educational research, because how teachers view themselves may determine their attitudes and behaviors in teaching (Beauchamp \& Thomas, 2009). Therefore, educational researchers have studied how teacher identity is formed and transformed in an attempt to provide recommendations for teacher professional development. In recent years, researchers have revealed the dynamic relationship between teachers' emotions and identity (Beauchamp \& Thomas, 2009; Day, 2011; Lasky, 2005; Zembylas, 2003b). Although the researchers may define teacher identity differently, they tend to agree with that teacher identity is inseparate from morality (Beauchamp \& Thomas, 2009; Beijaard, Meijer, \& Verloop, 2004). 
Studies on teacher identity and emotions are basically rooted in the general sociological perspective of identity (Burke \& Stets, 2009). According to the perspective, identity is the result of self-evaluation in terms of the cultural definitions of what is right or wrong, good or bad, and appropriate or inappropriate for oneself (Turner \& Stets, 2006). For example, Maclure(1993) explicitly stated that teacher identity is inescapably moral, because its claims are bound up with the evaluation of the conduct and thought of the teachers. Kelchtermans(1996) and Nias(1999) argued that teachers always define themselves as good or bad teachers according to the cultural definition of good teachers - the extent to which they can facilitate students' academic and personal growth.

Accordingly, identity is a container of self-meanings (Burke \& Stets, 2009). This means that social actors have a set of identities, which are hierarchically ordered, and a particular identity is more salient than others in a given situation. (Stryker, 1980). Social actors behave in certain ways in order to verify the salient identity. Research has illustrated that moral identity is always explicitly or implicitly more salient than social and role-identities, so social actors always attempt to perform socially and culturally defined moral acts to confirm their moral identity (Stets \& Carter, 2011). The sociological perspective of identity also maintains that identity falsification will arouse negative emotions, but identify verification will arouse positive emotions (Burke \& Stets, 2009; Stets, 2012; Stryker, 2004). Positive emotions will inform social actors that their identity is verified so they can maintain their behaviors; on the other hand, negative emotions will inform social actors that their identity is not verified, so they need either to re-verify the identity by changing their behaviors or to change their identity in order to justify their behaviors in that situation (Burke \& Stets, 2009).

On the basis of this perspective, educational researchers have indicated that teachers try hard to verify teacher identity in school settings (Maclure, 1993). Various studies have provided evidence to support the relationship between identity verification and emotions (Beauchamp \& Thomas, 2009; Day, 2011; Kelchtermans, 2005, 2011; Lasky, 2005; Zembylas, 2003a, 2003b). However, these studies suggest that teachers are subject to social constraints on identity verification, so it is easy for them to experience negative emotions (Kelchtermans, 2011). The most significant social constraint identified in the literature is educational reforms.

Similar to the research on the labor process of teaching in the context of education reforms reviewed above, studies on teacher identity also illustrate the effects of educational reforms on teachers' emotions (Kelchtermans, 2011). However, the difference between these two research approaches is that teacher identity research pays more attention to the effects of education reforms to identify verification than to the effects of the labor process of teaching. For example,Day (2002) illustrated that managerialist education reforms may create an identity crisis for many teachers because they were not able to foster students' grwoth which is regarded as the most important components of good teachers. Similarly, Lasky(2005) indicated that teachers prefer to pay attention to students' academic and personal growth, but the reforms may deprive them of the time and energy to do so. Therefore, teachers may be frustrated and disappointed by the reform, because the reforms tend to falsify their identity.

Research on teacher identity has demonstrated that teachers generally identify themselves as 
the ones who help students' academic, social, and moral development. To some extent, this kind of teacher identity is moral identity. This means that if teachers cannot verify it, they will perceive themselves as immoral or bad teachers and then experience negative emotions like shame and guilt (Kelchtermans, 2011). On the other hand, if they can verify it, they will perceive themselves as good and proper teachers, and so experience positive emotions like dissatisfaction and fulfillment (Kelchtermans, 2011). However, teachers are subject to many social constraints, like educational reform, which affect the process of identity verification. Therefore, it is easy for teachers to feel negatively at work.

\section{Common themes}

Table 1 summarizes the perspective, concern, and major arguments of the four common sociological approaches to teachers' emotions in the literature.

Table 1. The four sociological traditions in the study of teachers' emotion: perspectives, focuses, and major arguments

\begin{tabular}{|c|c|c|}
\hline Approach & Perspective & Concern \\
\hline $\begin{array}{l}\text { The labor } \\
\text { process of } \\
\text { teaching in } \\
\text { the context } \\
\text { of education } \\
\text { reforms }\end{array}$ & $\begin{array}{l}\text { Labor process } \\
\text { theory }\end{array}$ & $\begin{array}{l}\text { To improve teachers' } \\
\text { working conditions and } \\
\text { lives through studying } \\
\text { and criticizing how } \\
\text { education reforms } \\
\text { transforms teachers' } \\
\text { labor and labor process } \\
\text { through deskilling and } \\
\text { intensification. }\end{array}$ \\
\hline
\end{tabular}

Major argument

Teachers feel negatively because they perceive that they are forced to do a lot of work that is unrelated to teaching and education and have no educational value. They are forced to do the work, because the processes of deskilling and intensification caused by education reforms take over their control of the labor and labor process in teaching.

$\begin{array}{lll}\text { Emotion } & \text { Hochschild's To explore the nature } \\ \text { management } & \text { theory of of teaching and its } \\ \text { in teaching } & \begin{array}{l}\text { emotional } \\ \text { labor anpact on teachers' } \\ \\ \text { management emotional well-being }\end{array}\end{array}$

Teaching is interactive work with love and care and involves feeling and expression rules constraining teachers' emotional activities. The defined emotional activities may cause emotional dissonance for teachers, so that they may experience negative emotions. However, if they interpret that emotion management is conducive to teaching and learning, they may be willing to perform emotional labor and 


Social
interaction
in school
settings

Teacher

identity
Symbolic interactionism

settings

\begin{abstract}
Identity theory
\end{abstract}

To understand the role of emotions in the social interactions of teachers with students, parents, and colleagues, which may affect the quality of teaching and learning.

To investigate the formation transformation teacher identity in attempt to promote teacher professional development

and

of

management at work.

Emotional understanding between teachers, students, parents, and colleagues will affect their social relationships and interaction, and then teachers' emotions, which will influence further relationships and interaction. Emotional understanding may be influenced by the spatial and experiential patterns of closeness and/or distance between interacting parties.

in

verification will arouse teachers' positive emotions, but identity falsification will arouse teachers' negative emotions. However, there are many social constraints, such as education reforms, on the identity verification of teachers. Therefore, it is easy for teachers to experience negative emotions at work.

Although the four approaches have different perspectives, concerns and arguments, two common themes can be identified in relation to teachers' emotions. First, the four approaches reveal that teachers' emotions are related to the meanings they give to teaching. The approach of the labor process of teaching in the context of education reforms suggests that teachers value the work related to teaching and education, so they feel negatively if they are forced to do a lot of work unrelated to teaching and education. The approach of emotiona management in teaching reveals that teachers will feel positively about managing their emotions if they think performing emotional labor or management is conducive to teaching and learning. Otherwise, they may feel unhappy and sad having to manage their emotions in such a way that they do not correspond to their true feelings. The teacher identity approach explicitly points out that teachers identify themselves as the persons who facilitate students' academic, moral, and social development. If they perceive that they are successfully helping their 
students, they may experience happiness, satisfaction and a sense of fulfillment due to identity verification. If they fail to do so, they may feel shame, guilt, or negative emotions because of identity falsification. To some extent, all the approaches from different perspectives and concerns have reached a similar and even the same conclusion that teachers' emotions may be related to the fulfillment of the meanings they give to teaching - teaching is a profession to make a difference in students' lives.

Second, the four approaches respectively highlight that there are social constraints on the fulfillment of the meanings the teachers give to teaching. The approach of labor process of teaching in the context of education reforms and the teacher identity approach point out that education reforms is a macro-social constraint affecting this fulfillment. Another macro-social constraint is emotional culture in teaching in terms of the feeling and expression rules indicated by the approach of emotion management in teaching. On the other hand, the approach of social interaction in school settings suggests that social relationships and interaction among school members may be micro-social constraints.

Nevertheless, it seems that these studies overlook the social constraints at the meso- or institutional level. One of the significant meso-social constraints should be school administration. Sociologists of school organizations have debated whether school administrations are tightly coupled or loosely coupled systems (Ingersoll, 2003). A tightly coupled school system exercises tightly controls over teachers' work, but a loosely coupled school system provides teachers with a lot of autonomy. This is not to say that the sociological studies on teachers' emotions should resolve this debate. Rather, it is suggested that the studies should investigate how teachers feel in different types of school administrative systems, at least tightly coupled and loosely coupled systems. How do these two systems of school administration constrain teachers' fulfillment of the meaning they give to teaching? How do these two systems affect teachers' emotions at work? Moreover, the social constraints at the three levels may not function alone. Theoretically, they may interact with one another and then affect teachers' emotions. Therefore, in the future, the sociology of teachers' emotions should also pay attention to the interactive effects between the social constraints at different levels.

\section{Conclusion}

This article reviews four sociological approaches concerning teachers' emotions, including the labor process of teaching in the context of education reforms, emotion management in teaching, social interaction in school settings, and teacher identity. Although these approaches have different perspectives and concerns, this article notes that they may come up with similar conclusions about teachers' emotions. That is, teachers' positive emotions are aroused by the fulfillment of the meanings teachers give to teaching, while teachers' negative emotions are aroused by the failure to fulfill the meanings. Moreover, there are many social constraints, such as education reforms, emotional culture in teaching, and social relationships and interaction in schools, on the process of the fulfillment of teaching values or purposes. Thus, it is easy for teachers to experience negative emotions at work. 


\section{I Macrothink}

\section{References}

Anagnostopoulos, D. (2003). The new accountability, student failure, and teachers' work in urban high schools. Educational Policy, 17(3), 291-316. doi: 10.1177/0895904803017003001

Apple, M. W. (1982). Education and power. Boston: Routledge \& Kegan Paul.

Apple, M. W. (1986). Teachers and texts: A political economy of class and gender relations in education. New York: Routledge \& Kegan Paul.

Ashforth, B. E., \& Tomiuk, M. A. (2000). Emotional labour and authenticity: Views from service agents. In S. Fineman (Ed.), Emotion in organizations (2nd ed., pp. 184-203). London: Sage Publications.

Ball, S. J. (1994). Educational reform: A critical and post-structural approach. Buckingham: Open University Press.

Ball, S. J. (2003). The teacher's soul and the terrors of performativity. Journal of Education Policy, 18(2), 215-228.

Beauchamp, C., \& Thomas, L. (2009). Understanding teacher identity: An overview of issues in the literature and implications for teacher education. Cambridge Journal of Education, $39(2), 175-189$.

Beijaard, D., Meijer, P. C., \& Verloop, N. (2004). Reconsidering research on teachers' professional identity. Teaching and Teacher Education, 20, 107-128.

Blase, J. J. (2005). The micropolitics of educational change. In A. Hargreaves (Ed.), Extending educational change: International handbook of educational change (pp. 264-277). Netherlands: Springer.

Burke, P. J., \& Stets, J. E. (2009). Identity theory. Oxford: Oxford University Press.

Chen, M. Y. (2015). A literature review on teachers' emotional labor. Creative Education, 6, 2232-2240.

Comber, B., \& Nixon, H. (2009). Teachers' work and pedagogy in an era of accountability. Discourse: Studies in the Cultural Politics of Education, 30(3), 333-345. doi: 10.1080/01596300903037069

Connell, R. W. (1995). Transformative labour: Theorizing the politics of teachers' work. In M. B. Ginsburg (Ed.), The politics of educators' work and lives (pp. 91-114). New York Garland Publishing.

Day, C. (2002). School reform and transitions in teacher professionalism and identity. International Journal of Educational Research, 37, 667-692.

Day, C. (2011). Uncertain professional identities: Managing the emotional contexts of teaching. In C. Day \& J. C. K. Lee (Eds.), New understandings of teachers' work: Emotions and educational change (pp. 45-64). New York: Springer. 


\section{Macrothink}

Day, C., \& Lee, J. C. K. (Eds.). (2011). New understandings of teacher's work: Emotions and educational change. New York: Springer.

Denzin, N. K. (1984). On understanding emotion. San Francisco: Jossey-Bass.

Diefendorff, J. M., Richard, E. M., \& Yang, J. (2008). Linking emotion regulation strategies to affective events and negative emotions at work. Journal of Vocational Behavior, 73(3), 498-508. doi: 10.1016/j.jvb.2008.09.006

Dworkin, A. G. (2002). Teacher burnout. In D. L. Levinson, P. W. Cookson \& A. R. Sadovnik (Eds.), Education and sociology: An encyclopedia (pp. 659-664). New York: RoutledgeFalmer.

Evans, M. P. (2011). Revisiting emotional geographies: Implications for family engagement and education policy in the United States. Journal of Educational Change, 12, 241-255. doi: $10.1007 / \mathrm{s} 10833-011-9155-0$

Gong, S., Chai, X., Duan, T., Zhong, L., \& Jiao, Y. (2013). Chinese teachers' emotion regulation goals and strategies. 4 , 11(870-877).

Hargreaves, A. (1994). Changing teachers, changing times: Teachers' work and culture in the postmodern age. London: Cassell.

Hargreaves, A. (1998a). The emotional politics of teaching and teacher development: With implications for educational leadership. International Journal of Leadership in Education, 1(4), 315-336. doi: 10.1080/1360312980010401

Hargreaves, A. (1998b). The emotional practice of teaching. Teaching and Teacher Education, $14(8), 835-854$.

Hargreaves, A. (2000). Mixed emotions: Teachers' perceptions of their interactions with students. Teaching and Teacher Education, 16, 811-826.

Hargreaves, A. (2001a). The emotional geographies of teachers' relations with colleagues. International Journal of Educational Research, 35, 503-527.

Hargreaves, A. (2001b). Emotional geographies of teaching. Teachers College Record, 103(6), 1056-1080.

Hargreaves, A. (2002). Teaching and betrayal. Teachers and Teaching: Theory and Practice, 8(3), 393-407. doi: 10.1080/135406002100000521

Hargreaves, A. (2003). Teaching in the knowledge society: Education in the age of insecurity. Maidenhead: Open University Press.

Hargreaves, A., \& Lasky, S. (2004). The parent gap: The emotional geographies of teacher-parent relationships. In F. Hernandez \& I. F. Goodson (Eds.), Social geographies of educational change (pp. 103-122). Boston: Kluwer Academic.

Harris, K. (1982). Teachers and classes: A marxist analysis. London: Routledge \& Kegan Paul. 


\section{Ml Macrothink}

Journal of Sociological Research

ISSN 1948-5468

2015, Vol. 6, No. 2

Harris, K. (1994). Teachers: Constructing the future. London: The Falmer Press.

Hebson, G., Earnshaw, J., \& Marchington, L. (2007). Too emotional to be capable? The changing nature of emotion work in definitions of 'capable teaching'. Journal of Education Policy, 22(6), 675-694.

Helsby, G. (1999). Changing teachers' work: The 'reform' of secondary schooling. Buckingham: Open University Press.

Hochschild, A. R. (1983). The managed heart : Commercialization of human feeling. Berkeley: University of California Press.

Hopfl, H., \& Linstead, S. (1993). Passion and performance: Suffering and the carrying of organizational roles. In S. Fineman (Ed.), Emotion in organization (pp. 76-93). London: Stage Publications.

Hu“lsheger, U. R., Lang, J. W. B., \& Maier, G. n. W. (2010). Emotional labor, strain, and performance: Testing reciprocal relationships in a longitudinal panel study. Journal of Occupational Health Psychology, 15(4), 505-521.

Iltaf, H., \& Gulzar, A. (2013). Impact of expressivity and impulse strength on burnout and turnover intentions: Mediating role of deep acting. Journal of Business and Management, $7(4), 62-67$.

Ingersoll, R. M. (2003). Who controls teachers' work? Power and accountability in America's schools. Cambridge: Harvard University Press.

Isenbarger, L., \& Zembylas, M. (2006). The emotional labour of caring in teaching. Teaching and Teacher Education, 22(1), 120-134. doi: 10.1016/j.tate.2005.07.002

Jeffrey, B., \& Woods, P. (1996). Feeling deprofessionalised: The social construction of emotions during an OFSTED inspection. Cambridge Journal of Education, 26(3), 325-345.

Kelchtermans, G. (1996). Teacher vulnerability: Understanding its moral and political roots. Cambridge Journal of Education, 26(3), 307-323.

Kelchtermans, G. (2005). Teachers' emotions in educational reforms: Self-understanding, vulnerable commitment and micropolitical literacy. Teaching and Teacher Education, 21, 995-1006.

Kelchtermans, G. (2011). Vulnerability in teaching: The moral and political roots of a structural condition. In C. Day \& J. C. K. Lee (Eds.), New understanding of teacher's work: Emotions and educational change (pp. 65-82). New York: Springer.

Lasky, S. (2005). A sociocultural approach to understanding teacher identity, agency and professional vulnerability in a context of secondary school reform. Teaching and Teacher Education, 21, 899-916.

Leithwood, K., \& Beatty, B. (2008). Leadhing with teacher emotions in mind. Thousand Oaks: Corwin Press. 


\section{MInstitute Macrothink $_{\text {Int }}$}

Journal of Sociological Research

ISSN 1948-5468

2015, Vol. 6, No. 2

Lewig, K. A., \& Dollard, M. F. (2003). Emotional dissonance, emotional exhaustion and job satisfaction in call centre workers. European Journal of Work and Organizational Psychology, 12(4), 366-392. doi: 10.1080/13594320344000200

Maclure, M. (1993). Arguing for your self: Identity as an organising principle in teachers' jobs and lives. British Educational Research Journal, 19(4), 311-322.

Mok, K. H., \& Welch, A. R. (2002). Economic rationalism, managerialism and structural reform in education. In J. K. H. Mok \& D. K. K. Chan (Eds.), Globalization and education (pp. 23-40). Hong Kong: Hong Kong University Press.

Morgan, M., Ludlow, L., Kitching, K., O'Leary, M., \& Clarke, A. (2010). What makes teachers tick? Sustaining events in new teachers' lives. British Educational Research Journal, 36(2), 191-208. doi: 10.1080/01411920902780972

Na“ring, G. r., Brie"t, M., \& Brouwers, A. (2006). Beyond demand-control: Emotional labour and symptoms of burnout in teachers. Work and Stress, 20(4), 303-315.

Nias, J. (1996). Thinking about feeling: The emotions in teaching. Cambridge Journal of Education, 26(3), 293-306.

Nias, J. (1999). Teachers' moral purposes: Stress, vulnerability, and strength. In R. Vandenberghe \& A. M. Huberman (Eds.), Understanding and preventing teacher burnout: A sourcebook of international research and practice (pp. 223-237). Cambridge: Cambridge University Press.

O'Connor, K. E. (2008). "You choose to care": Teachers, emotions and professional identity. Teaching and Teacher Education, 24, 117-126.

OECD. (2005). Teachers matter: Attracting, developing and retaining effective teachers. Paris: OECD.

Oplatka, I. (2007). Managing emotions in teaching: Toward an understanding of emotion displays and caring as nonprescribed role elements. Teachers College Record, 109(6), 1374-1400.

Oplatka, I. (2009). Emotion management and display in teaching: Some ethical and moral considerations in the era of marketization and commercialization. In P. A. Schutz \& M. Zembylas (Eds.), Advances in teacher emotion research: The impact on teachers' lives (pp. 55-71). New York: Springer.

Philipp, A., \& Schu"pbach, H. (2010). Longitudinal effects of emotional labor on emotional exhaustion and dedication of teachers. Journal of Occupational Health Psychology, 15(4), 494-504.

Robertson, S. L. (2000). A class art: Changing teachers' work, the state, and globalisation. New York: Falmer Press.

Santoro, D. A. (2011). Good teaching in difficult times: Demoralization in the pursuit of good work. American Journal of Education, 118(1), 1-23. doi: 10.1086/662010 


\section{Macrothink}

Journal of Sociological Research

ISSN 1948-5468

2015, Vol. 6, No. 2

Saunders, R. (2013). The role of teacher emotions in change: Experiences, patterns and implications for professional development. Journal of Educational Change, 14, 303-333. doi: $10.1007 / \mathrm{s} 10833-012-9195-0$

Schutz, P. A., \& Zembylas, M. (Eds.). (2009). Advances in teacher emotion research. New York: Springer.

Scott, W. R. (1998). Organizations: Rational, natural, and open systems (4th ed.). Upper Saddle River: Prentice Hall.

Smyth, J., Dow, A., Hattam, R., Reid, A., \& Shacklock, G. (2000). Teacher's work in a globalizing economy. London: The Falmer Press.

Stets, J. E. (2012). Current emotion research in sociology: Advances in the discipline. Emotion Review, 4(3), 326-334.

Stets, J. E., \& Carter, M. J. (2011). The moral self: Applying identity theory. Social Psychology Quarterly, 74(2), 192-215.

Stryker, S. (1980). Symbolic interactionism: A social structural version. Menlo Park: Benjamin Cummings.

Stryker, S. (2004). Integrating emotion into identity theory. Advances in Group Processes, 21, $1-23$.

Sutton, R. E. (2005). Teachers' emotions and classroom effectiveness: Implications from recent research. The Clearning House: A Journal of Educational Strategies, Issues and Ideas, 78(5), 229-234.

Thoits, P. A. (1990). Emotional deviance: Research agendas. In T. D. Kemper (Ed.), Research agendas in the sociologoy of emotions (pp. 180-203). Albany: State University of New York Press.

Trentini, M. (2012). Teaching and the transmutation of emotions. International Journal of Work Organisation and Emotion, 5(2), 178-192.

Truta, C. (2013). Emotional labor and motivation in teachers. Procedia - Social and Behavioral Sciences, 127(4), 791-795.

Tsang, K. K. (2011). Emotional labor of teaching. Educational Research, 2(8), 1312-1316.

Tsang, K. K. (2013). Teacher emotions: Sociological understandings. Research Studies in Education, 11, 127-143.

Tsang, K. K. (2014). A review of current sociological research on teachers' emotions: The way forward. British Journal of Education, Society \& Behavioural Science, 4(2), 241-256.

Tse, T. K. C. (2005). Quality education in Hong Kong: The anomalies of managerialism and marketization. In L. S. Ho, P. Morris \& Y. P. Chung (Eds.), Education reform and the quest for excellence: The Hong Kong story (pp. 99-123). Hong Kong: Hong Kong University Press. 


\section{Macrothink}

Journal of Sociological Research

ISSN 1948-5468

2015, Vol. 6, No. 2

Turner, J. H., \& Stets, J. E. (2006). Moral emotions. In J. E. Stets \& J. H. Turner (Eds.), Handbook of the sociology of emotions (pp. 544-566). New York: Springer.

Wharton, A. S. (2009). The sociology of emotional labor. Annual Review of Sociology, 35, 147-165.

Whitty, G. (2002). Quasi-Markets in Education. In D. L. Levinson, P. W. Cookson \& A. R. Sadovnik (Eds.), Education and sociology: An encyclopedia (pp. 473-484). New York: RoutledgeFalmer.

Winograd, K. (2003). The functions of teacher emotions: The good, the bad, and the ugly. Teachers College Record, 105(9), 1641-1673.

Woods, P. (1999). Intensification and stress in teaching. In R. Vandenberghe \& A. M. Huberman (Eds.), Understanding and preventing teacher burnout: A sourcebook of international research and practice (pp. 115-138). Cambridge: Cambridge University Press.

Yin, H. B., \& Lee, J. C. K. (2011). Emotions matter: Teachers' feelings about their interactions with teacher trainers during curriculum reform. Chinese Education and Society, 44(4), 82-97.

Yuu, K. (2010). Expressing emotions in teaching: Inducement, suppression, and disclosure as caring profession. Educational Studies in Japan: International Yearbook, 5, 63-78.

Zembylas, M. (2003a). Emotions and teacher identity: A poststurctural perspective. Teachers and Teaching: Theory and Practice, 9(3), 213-238.

Zembylas, M. (2003b). Interrogating "teacher identity": Emotion, resistance, and self-formation. Educational Theory, 53(1), 107-127.

Zembylas, M. (2004a). Emotion metaphors and emotional labor in science teaching. Science Education, 88(3), 301-324. doi: 10.1002/sce.10116

Zembylas, M. (2004b). The emotional characteristics of teaching: An ethnographic study of one teacher. Teaching and Teacher Education, 20(2), 185-201. doi: 10.1016/j.tate.2003.09.008

Zembylas, M. (2005). Discursive practices, genealogies, and emotional rules: A poststructuralist view on emotion and identity in teaching. Teaching and Teacher Education, 21(8), 935-948. doi: 10.1016/j.tate.2005.06.005 